\title{
Fundamentos del Postmodernismo y el no estar ni ahí de la Universidad en (y de) Chile
}

\author{
Carlos Y. Valenzuela*
}

\begin{abstract}
Resumen: Se ha tratado de desprestigiar al postmodernismo y no se ha valorado su gran contribución a la cultura universal. El postmodernismo empieza a desarrollarse cuando el ser humano se da cuenta que no tan solo sus órganos de los sentidos pueden engañarlo, sino que también su intelecto, razón y sus facultades superiores más preciadas. Las caídas del positivismo y del racionalismo le abrieron la puerta, apoyado por la insuficiencia de la ciencia y la filosofía para entender el universo. La nomología (legalidad) ha tenido que resignarse frente a la ideografía (procesos irrepetibles e irreversibles) para entender el desarrollo universal. La antinomia del mentiroso, el teorema de Gödel, los procesos caóticos, la impredecibilidad, la incertidumbre, son parte de sus elementos sustantivos. El postmodernismo ha condenado a los ideologismos nomológicos o raciales que terminaron en las masacres de la Revolución Francesa, el Nazismo y las dos Guerras Mundiales, entre otros.

Palabras clave: antinomia del mentiroso, indecidibilidad Gödeliana, caída del positivismo, caída del racionalismo, nomología, ideografía
\end{abstract}

\section{Foundations of Postmodernism and the "not being interested" on the Universty in (and of) Chile}

\begin{abstract}
An attempt to discredit Postmodernism has taken place, yet its great contribution to universal culture has not been valued likewise. Postmodernism begins to develop when the human being realizes that not only their sense organs can deceive them, but also his intellect, reason and his most prized higher faculties. The fall of positivism and rationalism opened the door, supported by the failure of science and philosophy to understand the universe. The nomology (legality) has had to resign in front of the ideograph (unrepeatable and irreversible processes) to understand the development of the universe. The antinomy of the liar, Gödel's theorem, chaotic processes, unpredictability, uncertainty, are part of its substantive elements. Postmodernism has condemned the nomological or race ideologisms that ended in the massacres of the French Revolution, Nazism, and the two World Wars, among others.

Key words: antinomy of the liar, Godelian indecidibility, fall of positivism, fall of rationalism, nomology, ideographic
\end{abstract}

\footnotetext{
* Universidad de Chile. Santiago, Chile. Email: cvalenzu@med.uchile.cl
} 


\section{Fundamentos do pós-modernismo e do não estar lá da universidade (na) e (de) Chile}

Resumo: Temos tentado desacreditar o pós-modernismo e não tenha apreciado a sua grande contribuição para a cultura do mundo. O pós-modernismo está começando a se desenvolver quando o ser humano percebe que não só os seus órgãos dos sentidos podem enganar, mas também sua inteligência, a razão e as suas faculdades mais premiado superior. A queda do positivismo e do racionalismo abriu a porta, apoiado pelo fracasso da ciência e da filosofia para entender o universo. O Nomologia (lei) teve de demitir-se na frente do ideograma processos (irrepetível e irreversível) para entender o desenvolvimento universal. A antinomia do mentiroso, o teorema de Gödel, processos caótica, imprevisibilidade, incerteza fazem parte dos seus elementos substantivos. O pós-modernismo, condenou os ideólogos, ou nomológica corrida que terminou com o massacre da Revolução Francesa, o nazismo, e as duas Guerras Mundiais, entre outros.

Palavras-chave: antinomia do mentiroso, indecidibilidade Gödeliana, a queda do positivismo, a queda do racionalismo, nomologia, ideográfico

Recibido: 30.12.2009

Aceptado: 17.02.2010

$* * *$

\section{Introducción}

Hay una intencionalidad malévola en negar al Postmodernismo su status de periodo cultural importante para la humanidad. Viene de los integristas, del positivismo, racionalismo, serianismo o gravedismo, formalismo, solemnismo, conservadores, elitistas y cultores de un pseudo o sesgado intelectualismo. ¡El racionalismo ha muerto! ¡Viva el piñuflismo y la cultura guachaca particular y general! Esta última antinomia marca o titula al postmodernismo.

\section{La sospecha que la razón es falible y peligrosa}

Eubúlides y no Epiménides (Bochenski 1985), hace unos 2500 años, parece haberse dado cuenta por primera vez, con trascendencia universal, de que la racionalidad, el lenguajear, el buscar leyes generales o axiomas para conocer o demostrar, estaban inexorablemente condenados a poner sus propias fronteras de insuficiencia intelectiva, para conocer, entender o explicar la naturaleza. El mentiroso dice yo miento. Como es mentiroso, dice verdad, por lo que sigue mintiendo y, si miente dice verdad por lo que no es mentiroso y entonces miente. Incontables fueron los que se dedicaron a resolver esta antinomia; al menos Filites parece haber muerto por el intento. Apenas encontraremos en la Universidad de Chile un físico y un biólogo que se desvelen si no han resuelto un problema. Platón lo evitó. El momio, conservador y burócrata máximo del pensamiento, Aristóteles, dice que no ve problema en que una misma cosa sea falsa en algún respecto y verdadera en otro, con lo que se auto-acredita como inepto para penetrar en 
el problema mismo. Aristóteles, un intuicionista a rabiar (la virtud de los primeros principios es la intuición, ver en Ética a Nicómaco), no podía ver o aceptar que el sistema mismo de pensamiento pudiese estar errado o ciego (con cataratas aceptarán a lo más los defensores del Estagirita) desde la partida. La intuición, la razón, análisis o lógica como ha sido posteriormente traducido, el intelecto aciertan pero también son insuficientes, yerran o se equivocan irremediablemente, aún desde los primeros principios. Aristóteles es un gnóstico. La naturaleza y aún más Dios trascienden el principio de no contradicción concebido por el zapato chino de la mente humana. Se agregaron las antinomias de Aquiles que no alcanza nunca a la tortuga, o de la flecha que nunca puede llegar al blanco postuladas por Zenón de Elea (Alfonseca 1996) y, para ahorrar épocas, la del conjunto de los conjuntos impropios de Russell. El Barbero afeita a los que no pueden afeitarse a sí mismos, entonces, ¿quién afeita al barbero? Hasta la Edad Media se consideró que estas antinomias estaban erradas, pero, no se sabía dónde. Cerca de 1330, Tomás de Bradwardine (ver Verdú), considera que las antinomias son verdaderas y constituyen un dilema profundo de la lógica: escribe su Insolubilia (Gödel parece no tener idea de este libro).

\section{Origen y destino del Universo}

¡Otra voz! Como dijeron los militares y le cambiaron a la Universidad en Chile su goce y búsqueda de la verdad, bondad y beldad, por la preocupación administrativa y económica (cuadratura de caja) y la formación de profesionales que fueran dignos esbirros acríticos del sistema capitalista neoliberal y globalizador, para que le optimizaran su lucro, aún a costa de convertirse en un proletario acartonado o acartulinado (el cartón está muy caro). Escribía que otra voz vino del origen y destino del Universo. El descubrimiento del segundo principio de la termodinámica, que podríamos enunciar para todo lector como: ningún proceso natural es reversible, es decir no podemos volver exactamente a las condiciones iniciales en ningún proceso de la naturaleza. La naturaleza va para alguna parte. La flecha del tiempo de Boltzmann (Popper, Prigogine). En contraposición estaba el mito del eterno retorno (Nietsche). Como las configuraciones materiales de las partículas del universo son muchas pero finitas y el tiempo es infinito, todas esas configuraciones se repetirán aperiódicamente infinitas veces. Dimos un salto licencioso de la irreversibilidad a la irrepetibilidad (la demostración está fuera del alcance de este artículo). Según Boltzmann (y poniendo sus estudios al alcance de cualquier lector), el campeón de la flecha del tiempo, si se deja expandir 10 moléculas de gas, que estaban acumuladas en la mitad de un recipiente, al recipiente completo, nunca volverán a la mitad original del recipiente. Loschmidt y Zermelo (siguiendo el ejemplo para el lector, ver Popper y Prigogine) refutaron esta posición demostrando que la probabilidad de cada una de las 10 moléculas del recipiente total de encontrarse en un instante dado en UNA (no en LA) mitad inicial era _ y por lo tanto la probabilidad de las 10 moléculas de encontrarse en esa mitad, siendo las probabilidad de cada una independiente, era simplemente $\left(\_\right)^{10}=1 / 1024$. Boltzmann tuvo que resig- 
narse, se deprimió y se suicidó. Estaban tratando diferentes procesos que para el modernismo son lo mismo, pero no para el postmodernismo. El modernismo (Loschmidt y Zermelo) buscaba las leyes generales o nomologías (propiedades eternas de la naturaleza y de sus elementos constituyentes, léase a Bunge) desde donde todo pudiese ser predicho, con la única condición de saber el dato de las condiciones iniciales [Laplace el campeón de esta posición, sígase a San Martín (Ernesto), no el libertador, sino uno de los pocos matemáticos chilenos]. Boltzmann estaba pensando en las posiciones, velocidades y distribución histórica de esas 10 moléculas. La mitad del recipiente para Boltzmann no es ni la mitad física de ese recipiente, ni la mitad abstracta o nomológica (legal, a la Laplace), es ejemplo de una de las infinitas mitades en donde podrían estar esas 10 moléculas inicialmente. Boltzmann pensaba en la mitad histórica con trayectorias, posiciones y velocidades precisas de esas 10 moléculas, cada una con historia propia, cuya distribución real constituía esa mitad del recipiente. La mitad Loschmidt-Zermelo estaba sólo determinada en y por coordenadas del recipiente; la mitad Boltzmann estaba determinada por la configuración dada de las relaciones entre si de las 10 moléculas (colisiones incluidas) con nombre y apellido (nube histórica de moléculas) interactuando con las relaciones de cada molécula con el recipiente. La demostración Loschmidt-Zermelo es impecable en el plano matemático y lógico de las probabilidades, pero, por esa misma impecabilidad, es irremediablemente errónea en el plano de la realidad física o materio-energética, que nunca será totalmente reducible a nomología alguna. Es necesario pecar de particularidad irreducible para estar en la santidad de lo cierto. En la misma salsa abstracta de Loschmidt y Zermelo se cocina (demuestra) su error ya que ellos acuden al concepto abstracto de mitad-entorno que es igual para cada mitad-entorno posible del recipiente. Pero, ¿Cuántos mitad-entornos distintos posibles hay para Boltzmann? La respuesta es evidente: infinitos. Luego hay infinitos experimentos reales distintos según el entorno-mitad específico desde donde hayan partido las 10 moléculas. Una vez distribuidas las moléculas en el recipiente (y llegadas al estado de equilibrio termodinámico gaseoso), la distribución será la misma independientemente de la mitad-entorno desde donde hayan partido. La probabilidad condicionada de volver a cada una de las infinitas mitades diferentes posibles es 1/1024 (en paz con Loschmidt- Zermelo), pero la probabilidad de volver a una y a esa específica mitad es 0 (hay un número infinito no numerable de mitades), a no ser que las moléculas hayan conservado la información de la mitad que vinieron y del camino que hicieron para llegar al equilibrio. Podríamos también decir que la probabilidad de volver a constituir esa nube original con exactamente las mismas posiciones, velocidades y relaciones entre moléculas y el recipiente es también 0 . El Universo va hacia alguna parte, irremediablemente, lo sepamos o no. El error Loschmidt-ZermeloNietsche es el de todo el racionalismo, positivismo, intelectualismo modernista que postula que las abstracciones generalizadoras (leyes mentales) son las únicas válidas (constituyen la verdadera ciencia) y las condiciones históricas particulares son anecdóticas e irrelevantes para determinar la trayectoria (destino) de un proceso natural (la Miserable Miseria del Historicismo de Popper). Los entornos-mitades (abstracciones fundamen- 
tales para el modelo) al ser iguales, autorizan para trabajar con uno de ellos y extrapolar luego a todos. En la realidad cada entorno-mitad nada tiene que ver con el otro y, tratarlos como si fueran iguales es un error gravísimo de esta postura mental (fascismo epistémico). Pero hay otra condición que la matemática no toma en cuenta, y que la física debe tomarla. Se trata de la resiliencia del sistema. Cada vez que las moléculas se acumulan en un entorno produciendo una presión local superior a la del vecindario se genera un gradiente de presión que tiende a repartir las moléculas hacia el vecindario y no a conservarlas en ese entorno. Esto produce una fuerza que se opone a cualquier acumulación de moléculas y aunque la probabilidad matemática de que se acumulen en un entorno pequeño del recipiente existe, la probabilidad física y la duración del tiempo de concentración tienden a 0 mientras mayor es el número de moléculas y menor es el entorno; en la práctica esta es imposible. Cualquier cúmulo de moléculas lleva en si mismo las condiciones de su destrucción. No se oye en la Universidad en y de Chile ni siquiera un asomo de estas discusiones. Reconozcamos que por aquí, por allá, Tirapegui y algún otro caótico determinístico (ver Prigogine) han desarrollado este tema. Pero en la Física y Química chilenas estos caóticos, no creo que pasen de ser el 10\%. A estos procesos determinísticos $100 \%$, cuya trayectoria específica no puede saberse porque hay infinitas con igual probabilidad, los han denominado, desgraciadamente “caóticos”, pero no tienen nada de caos. Los tratan con matemática fractal (dimensiones con exponente fraccionario) y constituyen un importante elemento del postmodernismo. Los caotólogos (deterministas) han reivindicado a Boltzmann (ver Prigogine). Sin embargo, dado que no pueden determinar la trayectoria de un proceso han caído en el error de la confusión gnosoóntica y concluido que las trayectorias no existen. Porque no saben o no pueden determinarlas, entonces no existen. Esta actitud es resabio del modernismo. Ya entrarán de lleno en el postmodernismo. Decir que un electrón no tiene trayectoria histórica, es decir que no ha pasado por ninguna parte (lástima la doble negación del castellano). La relevancia de este problema involucra a la Filosofía, Teología, Astrofísica, Termodinámica, Física cuántica y relativista a través de la teoría generalizada de la evolución o del origen y destino del Universo. ¿Cómo se originó y se mantiene la estructura dinámica del universo, entendida como el origen de las posiciones relativas de todos sus elementos y sus modificaciones en el tiempo? A menudo se llama a esto información. Hagamos una distinción gnoso-óntica. La información es una abstracción que sólo está en la mente (gnosia) de algunos humanos. Las posiciones dinámicas relativas de los elementos del universo pertenecen a su ser (ontos). En el Big-Bang la energía y masa era 0 (según algunos, otros discrepan), luego no había distribución estructurada de la materia y energía [relaciones (ontos) ni información (gnosos)]. ¿Como apareció esa estructuración? Cuando una galaxia es absorbida por un hoyo negro ¿Desaparece toda estructuración? Stephen W Hawking está tratando de demostrar que no desaparece la información, aunque anteriormente parece que todos aceptaban que desaparecía. Si en el Big-Bang no había información (ni gravitación, ni relatividad, ni nomología) y cuando el hoyón negro más grande absorba a todo el universo y desaparezca toda información ¿Cómo podrá justificarse, entenderse o explicarse la existencia de in- 
formación durante ambos eventos? Parece ser que Dios, seres transdimensionales o trans-materio-energéticos son inevitables, al menos como posibilidad (diablos y ángeles parece que algo de información tienen y no la han sacado de la Universidad de Chile). Si SW Hawking cree que la información es eterna, entonces es más creyente en Dios que Santo Tomás de Aquino, nada más que él llama Dios al factor que originó y mantiene la información.

Nota epistémica. Se ha denominado nomológico o nomotético al componente legal de los procesos naturales, e idiográfico (idiosincrásico en biomedicina) a su componente peculiar, particular o histórico. Prefiero hablar de componente nomológico e idiológico (no confundir con ideológico). Loschmidt-Zermelo, el positivismo, el racionalismo y el modernismo suponen que la ciencia sólo tiene que ver con lo nomológico, Boltzmann intuye que lo idiológico es la intención fundamental de la ciencia, lo que será demostrado por el postmodernismo. Lo nomológico es parte de lo idiológico (la nomología tiene una historia única e irrepetible).

\section{Don Quijote de la Mancha y el destacado cientista-filósofo Sancho Panza}

Una tercera fuente posmodernista viene del Renacimiento y especialmente del español. Don Alonso de Quijano, más conocido por su ciudad natal y de vida como Don Quijote de la Mancha, escribió la biografía de Miguel de Cervantes, quién terminó invirtiendo la situación y aparece como el autor de la novela Don Quijote. Don Quijote fue un posmodernista a rabiar. Se mofó de la razón, con mucha razón, cuando en razón de Aldonza Lorenzo, su amada Dulcinea, raciocina: la razón de la sin razón, que a mi razón se face, de tal modo mi razón enflaquece, que con razón me quejo de la vuestra fermosura (mi memoria puede razonablemente traicionarme). Es una pitanza posmodernista fantástica. Don Alonso era versado en lógica y en los grandes problemas del mentiroso, de la insolubilia de Bradwardine, de la recursividad lógica, y es justo precursor de Kurt Gödel. No dice la historia si Don Alonso aconsejó a Don Sancho Panza para que resolviera el asunto de los jueces tras el puente, pero es claro que alguna relación, en esto tuvo. Yo creo que fue al revés, Sancho Panza era el pensador profundo y sólo aparecía su devoción a las altas especulaciones intelectuales, estéticas y morales, cuando el pernil de chancho, bife chorizo o las deliciosas pastas que harían palidecer de envidia al tano más chovinista, se lo permitían. Panza y no de Quijano precede a Gödel. Los jueces al otro lado del puente preguntaban al transeúnte, que acababa de pasarlo, qué iba a hacer en este lado del río. Los jueces sabían todo lo que los seres humanos iban a hacer. Si decía verdad lo dejaban pasar, si decía mentira lo ahorcaban. Muchos pasaron y pocos fueron ahorcados. Hasta que llegó uno que pasó el puente y dijo a los jueces, frente a la pregunta sobre su destino: Ustedes me ahorcarán. Si lo ahorcaban dijo verdad y tenían que no ahorcarlo (dejarlo pasar); si lo dejaban pasar, dijo mentira y tenían que ahorcarlo. Despa- 
voridos llegaron donde Don Sancho, gobernador de la Ínsula, que concluyó: déjenlo pasar, porque de las dos alternativas es la mejor. Cual Alejandro cortando el Nudo Gordiano, resolvió el problema de un golpe vivencial, irracional, pero ético. Dirán los juristas y expertos en Derecho, con caras circunspectas, llenas de seriedad y solemnidad: In dubio, pro reo. ¡Qué dubio ni qué ocho cuartos! La insolubilia o indecidibilidad no es una duda, es una verdad cruel e impía contra la mente y la razón humana: Srta. Mente o Doncella Razón, Uds. son muy limitadas y falaces. A propósito de falaces, se ha cuestionado en estos tiempos el estado de señorita de la mente o de la razón, algunos dicen que son, más bien, señoras recatadas (argumentos fuera del alcance de este artículo). ¿Son la mente o la razón vírgenes o asépticas?

\section{La tristeza de las masacres humanas para buscar su felicidad}

Por otra parte la historia no los absolverá. El racionalismo nació después que la Iglesia Católica puso a las obras de Descartes (Cartesius) en el Î́ndice de libros prohibidos (Ver en Descartes: Discurso del Método). Los secularistas o laicistas tomaron como bandera de lucha el racionalismo cartesiano; encontraron un sustituto para Dios nacido de la Iglesia misma: la razón, que según Hegel es Dios mismo (Valenzuela 2001). Muchos filósofos posteriores, especialmente Spinoza fundamentaron su filosofía en este modo de pensar. La prohibición parece estimular la lectura. Algunos neurocientistas actuales, que no entienden a Descartes, hablan del error de Descartes, pues no incluyó la inteligencia emocional, o los afectos, o los valores u otras funciones mentales en su forma de pensar. Falso, Descartes pudo haber reflexionado: defeco luego existo, y habría sido lo mismo (hay gente que tiene mente excrementicia o coprofrenia). No entraremos en esa discusión para iniciados escatológicos. Iremos al humor teológico más profundo y postmoderno. Descartes encontró su método gracias a una manda que hizo a la Virgen de Loreto, que no tiene poder para hacerlo y se lo pide al Espíritu Santo. Como Descartes encontró ese método y pagó su manda, podemos suponer que, de existir, fue el Espíritu Santo el que en última instancia inspiró y creó el método por medio de Descartes. Entonces la inspiración del Espíritu Santo ante la petición de la Virgen de Loreto fue puesta en el Catálogo de los libros prohibidos por la Iglesia Católica. Esta prohibición ¿Fue también inspirada por el Espíritu Santo? Me imagino al Espíritu Santo, todo compungido comunicando al Padre y al Hijo que su inspiración, con complicidad de la Virgen de Loreto, fue condenada por la Iglesia Católica. Los teólogos reclamarán que las premisas están mal construidas, que hay mala intención, que no se trataba de esto, qu'esto quel'otro. Nada de eso, se trata de que Dios no es tan sólo Amor, Dios es también Humor y gratuito. Los laicistas o secularistas no lo han hecho mejor, por la rationalité de la Ilustración y en seguida por la liberté, egalité y fraternité lanzaron la Revolución Francesa que mató a cerca de 500.000 personas. Sólo en la Vandea (Vendée) mataron a más de 100.000 católicos realistas 
(me lo contó un descendiente de esos pueblos, ver en de la Cierva). Pretendiendo, la racionalidad, la justicia, la paz, la armonía de los pueblos, Napoleón uno de los peores verdugos de Europa (sobrepasado sólo por Hitler) produjo directa o indirectamente más de 2.000.000 de muertos. La Primera Guerra Mundial mató a más de 10.000.000. La Segunda mató a más de 60.000.000. Se calcula que en el holocausto murieron cerca de 6.000 .000 de judíos. Pero si el enfrentamiento entre, por un lado el eje ideológico-religioso Anglo-USA-Sionismo (Fascismos internacionalistas) y por el otro el Nazismo-Fascismo-Japón (Fascismos nacionalistas) o cualquier otro que se dé, van a cobrar el precio de casi 100.000.000 de muertos cada vez que se enfrenten, la humanidad no puede tener paz. Como si fuera poco las guerras posteriores realizadas por EEUU, en Corea, Viet-Nam y numerosas intervenciones en otras partes del mundo, para salvar la libertad de los pueblos, han matado a varios millones en el mundo y a centenares de miles de estadounidenses. La Revolución Soviética mató a más de 15.000.000 de personas en aras de la sociedad sin clases. Es directo, que si una clase social mata a las otras, quedará ella sola y constituirá una sociedad monoclásica. La instalación de Israel y sus guerras ha llevado a cerca de un millón de palestinos y árabes y a decenas de miles de israelíes muertos. Las masacres, torturas y vejaciones de las revoluciones político-ideológico-religioso-militares de América Latina, son una vergüenza para la humanidad. Las invasiones de Afganistán e Irak promovidas por el eje USA-Anglo-Sionismo, además de las muertes provocadas en ambos bandos, son la fuente de mayor inestabilidad para la paz del mundo. No podemos mencionar todas las matanzas étnicas de Armenios, Kurdos, Sudaneses, etc. Las persecuciones de los cristianos en el Imperio Romano cobraron millones de muertes; aún hoy las persecuciones religiosas le cuestan a la Iglesia Católica cientos o miles de muertes anuales. Las luchas entre el Hinduismo y el Islam en India han cobrado miles o millones de muertos. Los regímenes sociales han producido y producen más sufrimiento que todas esas matanzas juntas; los regímenes esclavistas, mercantiles, de explotación capitalista, de estratificación social y de castas no han tenido misericordia con varones, mujeres o niños. Es cosa de ver los muertos por desnutrición y enfermedades laborales en la minería, la construcción (aún de las pirámides), la explotación agraria. Todas estas matanzas han sido racionalmente justificadas por diferentes razones esgrimidas por los racionales agentes en discordia. ¿Puede el mundo creer en la razón, el uso de la ciencia, el uso de la técnica, la valoración del ser humano que ha hecho el Modernismo? Siguiendo a Cristo que dice: por sus frutos los conoceréis, parece que no. El posmodernista no les cree, porque sí, a estas aristocracias fascistas transnacionales, públicas o secretas, que no dan puntadas sin hilo, es decir que, si invierten para el desarrollo es porque van a sacar a la postre mas provecho, sea en poder, capitales o posiciones en el concierto mundial. Tampoco le cree, porque sí, a Su Santidad el Papa o a Su Santidad el Dalai Lama, ni a otro líder político, ideológico o religioso. El mundo progresa en sentido de disposición de tecnología, pero en cuanto al poder, al dinero, a la información o a la propiedad, unos pocos, que cada vez más son menos, progresan mucho mas que los otros. 
Son los que están detrás de la globalización, último bastión del modernismo nomológico. La Universidad de Chile no ha estudiado ninguno de los movimientos religiosos o ideológicos, renunció a tener una Facultad de Religiones e Ideologías. Renunció a la Facultad más preciada por su fundador Andrés Bello: la Facultad de Teología(s). Las luchas beato-masónicas la expulsaron de la Universidad de Chile, después de haber cumplido un itinerario importante por cerca de 90 años, y con ello se perdió el pluralismo en la trascendencia de lo más preciado que tiene el ser humano: los proyectos de su felicidad. Hace poco expulsó vergonzosamente al Director del Instituto de Ciencias Políticas. Es curioso que el Modernismo buscando el respeto a la disidencia terminó en el fascismo más brutal y rígido, el fascismo de, lo que el poderoso cree, su razón. De paso no olvidemos que generado en esas luchas beatosecularistas, nuestro escudo reza: por la razón o la fuerza, y no es casualidad. El legalismo científico (nomología) está en la base del legalismo ideológico. Los pueblos deben comportarse como el legalismo ideológico o religioso dice, morir o sufrir hasta adaptarse a esa nomología. Todos deben al fin adaptarse al corte por la misma tijera, a la orden del partido, a vestirse el mismo mameluco. La realidad concreta de los pueblos poco importa, porque es una menudencia irrelevante para la interpretación social-ideológica nomológica. Por eso, la globalización es el último alarido del modernismo fascista internacionalista que pretende que las especificidades culturales de los pueblos y los pueblos mismos desaparezcan si no se adaptan. El racionalismo modernista llevó a una concepción legalista fundada en una opción ideológica sustentada por la sacrosanta razón a la cual todos debían someterse, porque la razón es en última instancia Dios. Esta visión netamente gnóstica inspiró al mercantilismo, capitalismo, marxismo, liberalismo y neoliberalismo. El paraíso está en la tierra y se encuentra por la concepción racional de un ser socioeconómico y de la actividad productiva. Las formas de producción y del mercado son Dios y el ser humano debe vivir para producir y concurrir al mercado y no, el mercado y las formas productivas deben ponerse al servicio del ser humano para que se libere y pueda dedicarse a su expansión y cultivo espiritual, lúdico y mental integral. Según estas visiones gnósticas nomológicas la distribución del poder, riqueza, información, conocimiento o prestigio, con que nacen los seres humanos, no pueden ser cuestionadas porque traducen la voluntad inequívoca de ese Dios gnóstico (inventado por la mente humana). El itinerario libre que cada ser humano puede tener en su proceso de realización personalizada, única, irreversible e irrepetible, debe ser juzgado, por no poderse someter a una legalidad racional, como espurio, peligroso y debe ser reprimido o no financiado. Así, desaparece también la verdadera autonomía universitaria. La universidad que tiene como función fundamental ser la conciencia crítica, lúcida, libre y autónoma de una sociedad, en si misma es peligrosa y debe desaparecer para convertirse en una máquina formadora de profesionales acríticos. La Universidad de Chile, obediente a la ley LOCE, ha cumplido y cumple a cabalidad este objetivo. No sólo no ha entrado en el postmodernismo, sino que ha retrocedido al feudalismo, como la LOCE estipula. 


\section{¿Por qué la persecución, matanza y condena de los científicos y sus obras?}

La Iglesia Católica ha pedido perdón por la condena a Galileo. No ha quedado claro porqué lo ha pedido, ya que no quedó claro porqué lo condenó. Parece ser que después de un traslado de documentos (¿'robo?) realizado por Napoleón desde el Vaticano, una gran parte del proceso se perdió, así que parece que no lo sabremos nunca. No se puede enmendar la conducta que no se conoce o aquello que no se sabe que está errado. Mucho se ha hablado de los horrores de la Iglesia Católica contra científicos como Galileo o Bruno a quién quemó. Esto ha tapado la persecución que todos los científicos y buscadores de la verdad han sufrido, en todas las épocas, por parte de los que ostentan el poder, de los que se consideran pensadores libres, de los religiosos o de los políticos. Muchos presocráticos, Sócrates mismo, los Académicos (con Platón a la cabeza), los del Liceo de Aristóteles, fueron acusados de pervertir a la juventud apartándola de Dios (parece que nada ha cambiado). A Sócrates lo obligan a suicidarse. Maimónides es expulsado del Judaísmo, acusado de haberse pasado la sufismo islámico y finalmente el Islam, que produjo uno de los avances culturales intelectuales más grandes que la humanidad conozca, renuncia a la intelectualidad científica, al sufismo y se vuelve al cultivo de la religión sin contaminación con la intelectualidad (esta tendencia ha derivado en el integrismo y fundamentalismo islámico). Spinoza es expulsado de la Sinagoga. Muchos científicos medievales y renacentistas mueren acusados de brujería, hechicería o, como se juntaban sólo varones en sus cofradías científicas, acusados de homosexualidad demoníaca. El camino de la anatomía está tan plagado de cadáveres de los anatomistas como de los disecados por ellos. Los Calvinistas queman a Servet. No solo la Iglesia Católica, sino que todas las Iglesias Cristianas se opusieron a la concepción Copernicana o Galileana. Esta oposición se inició cuando Aristarco de Samos (también astrónomo), hacia el 250 A.C. postuló que la tierra giraba en torno al sol generando las estaciones y giraba en torno a su eje para dar el día y la noche; fue perseguido y casi muerto, acusado de atentar contra los dioses. Antes que Copérnico y Galileo, muchos escolásticos de la Escuela Franciscana (Nicolás de Oresme, entre otros) daban por sentado las ideas de Aristarco. Roger Bacon (franciscano \pm 1260 DC), refundador del método científico experimental, fue encarcelado por sus mismos hermanos de orden. La Iglesia Católica antes del problema con Galileo aceptaba como posibilidad la idea de Aristarco. Fueron los protestantes los intransigentes con Copérnico (ver libro de Renato Espoz), y al parecer la Iglesia Católica no quiso ser menos Protestante que los Protestantes en su adicción a la Biblia y junto con los Luteranos condenaron las ideas de Aristarco, modificando el libro de Copérnico y condenando a Galileo. El Cardenal Bellarmino que hoy es Santo, participó en la condena a Galileo, que sabemos errada, Galileo que estaba en lo correcto, no solo no es santo, sino que no se ha reivindicado su obra como lo merece. Para qué hablar de la oposición de las Iglesias Cristianas a la Evolución. Hace 60 años los libros de Teilhard de Chardin estaban prohibidos por la Iglesia Católica. Recientemente el ala conservadora del Protes- 
tantismo estadounidense, con Bush a la cabeza, ha criticado severamente a la evolución por Selección Natural (Darwiniana) postulando la evolución por el Diseño Inteligente. Como tienen poder, han obligado, por ley, a enseñar esta nueva postura en las escuelas junto a la evolución selectiva. En la Universidad de Chile no se oye discusión de ningún diseño, sea inteligente o idiota. A lo más se escucharon los destemplados denuestos Brncicianos contra el neutralismo Kimuriano o, Rothhammerianos contra el pan-seleccionismo. Es curioso que la Iglesia Católica en estos últimos 15 años se haya puesto furibundamente de parte del neo-Darwinismo y haya condenado al Diseño Inteligente (Cardenal P Poupard) como incompatible con la hermenéutica actual del Antiguo Testamento. Me pregunto si habrán académicos en la Universidad de Chile que puedan entender lo que actualmente hermenéutica significa (sea a la Dilthey o a la Heidegger). La Beata Unión Soviética no les fue en saga a las iglesias cristianas. Se les puso a los dirigentes del Partido (Stalin) que la genética de Mendel, que establecía que los caracteres estaban determinados por factores internos particulados permanentes, era contraria al postulado marxista que el ser social determina la conciencia social. Nada podía ser permanente, menos en la mente humana. La mente humana no tenía determinantes genéticos. En la agricultura la herencia de los caracteres adquiridos era suficiente. Los genetistas Mendelianos fueron perseguidos, enviados a manicomios o a campos de concentración. Se hundió la genética en la Unión Soviética, no realizaron la revolución genético-agrícola y terminaron comprándole trigo a sus archirivales ideológicos capitalistas como EEUU o Argentina (a través del mercado internacional, por cierto). La persecución de las ideas científicas críticas o novedosas y de los autores de ellas, se hace ahora más sofisticadamente. No se financian proyectos que aparentemente no tengan aplicación, no se publican esos trabajos. Thomas Kuhn nos ha ilustrado sobre lo difícil que es la ciencia paradigmática, debido a los grupos de poder que se han adueñado de los centros de publicación o de información científica e imponen sus nomologías.

\section{La alternativa Postmoderna}

El Modernismo con Laplace a la cabeza, creía que todo suceso natural era debido a una causa precedente y las causas eran dadas por los elementos del universo y sus propiedades conocidas como leyes. Es la visión nomológica del universo. Era cosa de conocer las leyes de la naturaleza para poder determinar o predecir todo proceso natural. No había gato encerrado. Las leyes son para las ciencias naturales como los axiomas son para la matemática, para la cual un suceso o proceso físico, puede ser equivalente a un teorema. Hilbert y Russell se dieron a la tarea de demostrar que todo teorema, en un campo matematizable, podía ser demostrado con un sistema consistente de axiomas, aunque estos fueran en número infinito. No sabían que Sancho Panza, Alonso de Quijano y mucho antes Bradwardine, se les habían adelantado. ¿Es posible encontrar un sistema de axiomas desde donde todo teorema matemático puede ser demostrado? Hilbert y Russell eran empeñosos, pero no les dio para resolver esta pregunta. No podemos entrar 
en los sistemas lógicos aritmetizables de Gödel, así que haremos una semblanza a las antinomias del mentiroso y a la de los jueces que consultan a Sancho Panza. Proponemos un teorema que dice: Yo no soy decidible (demostrable) por el sistema de axiomas que se refiere al contenido de mis elementos, sus relaciones y leyes de construcción. Simplemente: Yo no soy demostrable por estos axiomas. Supongamos que se llega a demostrar por esos axiomas que este teorema es verdad, es decir no es demostrable, es decir no hay axiomas suficientes para demostrarlo. Llegaríamos a la conclusión (como en el mentiroso) que la proposición planteada es verdadera y falsa a la vez (es demostrable que no es demostrable o bien hay axiomas por los que se prueba que no hay axiomas que lo demuestren). La otra alternativa es que no sea nunca demostrable ese teorema. Entonces si queremos mantener la sanidad mental tenemos que aceptar que todo sistema nomológico o axiomático o 1) Es incompleto y habrá un número infinito de teoremas que no pueden demostrarse con esos axiomas o sucesos que no pueden predecirse con esa nomología o 2) El sistema por hacerse completo se hace inconsistente y entonces habrá infinitos teoremas que podrán demostrarse como verdaderos y falsos a la vez; en el caso de la nomología podrá predecirse cualquier cosa de cualquier proceso incluso posibilidades contradictorias, o bien nada podrá predecirse. Kurt Gödel publica su teorema sobre sentencias indecidibles en 1931. En justicia debería ser el teorema de Panza-Gödel (Eubúlides-Bradwardin-Panza-Gödel), pero la comunidad científica o filosófica es demasiado modernista y poco madura para aceptar esta proposición. Ambos tuvieron un sino vital y final extremadamente distinto debido a su actitud con la mesa. Mientras Panza deliraba por una plena de manjares, afición que lo llevó a morir de diabetes e hipertensión arterial, entre un lechón de jabalí con salsa de ciruelas y un condumio bien regado; Gödel murió de hambre debido a la obsesión paranoica de no comer porque lo querían envenenar. Gödel muere en Princeton (1978), en la misma cuidad donde 23 años antes moría Einstein; había nacido en Brno (1906), 41 años después que, en la misma ciudad, Mendel realizara su descubrimiento de la herencia particulada (y 22 después de la muerte de Mendel en Brno en 1884). Einstein y Mendel terminaron estudiando los grandes movimientos de partículas, sea en el movimiento Browniano sea en la meteorología. Mendel vislumbró el postmodernismo con sus leyes, Einstein es uno de los últimos modernistas, que para mantener la nomología, homogénea en cualquier parte, curva el espacio, el tiempo o cualquier elemento auxiliar de la mente. El aporte Panza-Gödel es trascendente y el punto más importante del post-modernismo. Para Panza, los seres vivos y en especial los humanos encierran una riqueza procesal-vivencial (idiológica) imposible de reducir a leyes intelectuales o del derecho; son procesos irreversibles e irrepetibles superiores a los intelectualismos o racionalidades humanas. Para Gödel aún los números son mucho más ricos en contenido de verdad que cualquier teorema o axioma que se refiera a ellos. Pero Panza supera a Gödel, pues aún Gödel permanece en las sentencias, proposiciones, hipótesis, teoremas, axiomas, es decir intelectualidades; mientras Panza se pronuncia sobre procesos irreductibles a ser tratados por proposiciones, intelectualidades o racionalidades. Panza señala que la ciencia es entender el suceder, y no meramente explicarlo, para aplicarlo hacia la felici- 
dad del ser humano (dejar libre al reo). La ciencia trasciende las teorías, hipótesis, método, modelos, inducción, deducción, lógica, análogos que son simples herramientas para alcanzar el goce de la armonía de una resonancia con el universo; la ciencia acorrala al universo o a la naturaleza hasta que sueltan la pepa firme. Eso es la verdad, un correlato positivo resonante entre (al menos) dos procesos. Toda resonancia es armónica y creadora de existencia, por lo que la verdad, la bondad y la beldad son facetas de una misma vivencia, que especificada en una intencionalidad de objetivo constituye a la ciencia, no tan sólo humana, sino que universal. Desde Platón en adelante la universidad es la búsqueda de la verdad (ciencia, filosofía), beldad (estética, arte) y bondad (ética y humanidades) integralmente. Ninguna candidatura de rector de la Universidad de Chile ha tenido como punto esencial esta búsqueda, en los últimos 35 años. La Universidad de Andrés Bello si la tuvo.

Hemos visto que el postmodernismo le ha puesto un epitafio a la razón (adiós a la razón escribirá Feyerabend, se le adelantó Don Quijote 370 años) y a la suficiencia nomológica, ha realzado los procesos irrepetibles e irreductibles (idiológicos) por encima de cualquier nomología. No es raro que proliferen las metodologías cualitativas, de caso único, de procesos particulares irrepetibles, de historias de vida, de narrativa, etnografía, etc. En el postmodernismo la ciencia nomológica continúa, pero la ciencia ya no pretende que la nomología sea lo único, ni lo más importante. Es la consistencia lo importante, la coherencia, el estándar único del científico, el no a la impostura y al engaño. En la vida cotidiana el postmodernismo exige consecuencia, se alegra por la existencia irreducible de la diversidad ideológica, política o religiosa. No busca forzadamente el consenso. La Ética discursiva de Appel y Habermas es un alarido póstumo del modernismo. Mucho más importante que la forma en que se relacionan los seres humanos es la vivencia profunda del contenido de cada ser humano como proceso interactivo con el universo. Puede ser Católico, Nazi, Satánico, Evangélico, Musulmán, Sionista, Comunista, Hindú, Budista, Animista, Agnóstico, Gnóstico (Eliade et al. 1991) o tener cualquier ideología o religión y que bueno que así sea; pero no venga a imponer directa o indirectamente sus creencias, ni sus concepciones de mundo a los demás. El posmodernista exige transparencia y la exigencia de esta transparencia (glasnost) hizo caer a la Unión Soviética. No acepta poderes ocultos que dirijan el mundo, que tantas muertes han causado. ¡Que todos los movimientos se presenten con sus intenciones completas! ¡Nada de cartas bajo la manga ni de hacer comulgar con ruedas de carretas! ¡Nada de supuestos económicos de origen divino contra los cuales no se puede ir! El posmodernista no les cree a las Instituciones nomológicas, porque sí. Las Instituciones que, en su espíritu, pretenden la felicidad del ser humano y se ponen a su servicio, han sido infiltradas por narcisistas buscadores del poder y de su beneficio, que desde sus cúpulas, han traicionado su espíritu y han causado muertes, torturas, sufrimiento evitable y miseria humana. Pero, las Instituciones tienen culpa pues no han sabido deshacerse de esos renegados usurpadores del poder confrontando sus actuar con el espíritu. Por eso el postmoderno no les cree. Es patético que el Judaísmo, Cristianismo 
e Islam, que están basados en la Biblia cuyo Pentateuco manda repartir de nuevo todas las propiedades cada 50 años y amar al prójimo como a si mismo, no observen estos mandamientos en sus organizaciones sociales (esclavitud, mercantilismo, capitalismo, liberalismo y neoliberalismo), y estamos hablando de 3.000.000.000 de seres humanos. La compasión Budista es posible que la siga el Dalai Lama y un puñado de sus seguidores, pero no los 300.000.000 de budistas. Las instituciones y la nomología son tomadas en cuenta en tanto dan lineamientos generales y en su espíritu, pero el postmoderno valora más al individuo, que por genoma y por historia o ambiente es único, irrepetible e irreversible y trasciende a las instituciones y nomologías. No faltan los eternos, que han subsistido en todos los regímenes y que dicen ser neutros, a-políticos, a-religiosos, an-ideológicos, a-valóricos, an-éticos, a-morales, an-emotivos, an-afectivos (miembros del club del a-panismo), ellos son laicos o seculares absolutos, a todos les dicen si, pero cuando quedan solos, hacen lo que les conviene, con una ideología bien precisa, pero que no se atreven a confesar públicamente y ni siquiera ante si mismo. Amebas éticas, gelatinas morales, chicles mentales con psiquis aleatorias, corchos que han flotado en todas las aguas, incluso en las servidas, y el postmodernismo les tirará la cadena, exigiéndoles transparencia en sus posiciones. La gran visión del Post-Modernismo es el proceso dinámico de la Evolución del Universo, con la historia de las nomologías y las particularidades irreductibles. En los seres bióticos es la genómica que restablece la evolución y a San Francisco. Cada ser humano (o vivo) tiene un genoma que nunca se ha dado, ni nunca se dará nuevamente, ni siquiera los gemelos monocigóticos son idénticos genómicamente. Por otra parte en la filogenia se ha descubierto que todos los seres vivos son hermanos ya que proceden del mismo origen genómico. Dos seres humanos en 1000 de sus bases nucleotídicas que codifican para proteínas son iguales en 999 y diferentes en 1 . El genoma humano desbarató todo intento de fundamentar materialmente el racismo, machismo, clasismo, estratismo socioeconómico, distribución asimétrica de la riqueza, de la propiedad o del poder. Todas estas desigualdades socio-económico-culturales proceden de las decisiones humanas y pueden fácilmente ser revertidas por otras decisiones humanas. Se solucionó de un golpe epistémico el problema de la igualdad y desigualdad de los seres humanos. Somos fundamentalmente iguales $(99,9 \%)$ y distintos $(0,1 \%)$. A pesar de esta igualdad algunos ganan en Chile \$100.000.000 mensuales frente a una inmensidad (cerca de un millón) que gana sólo \$100.000 y frente a otra inmensidad (cerca de 500.000) que ganan $\$ 0$ pues están cesantes. El genoma humano nos ha revelado que el único sistema de convivencia que podría generar justicia y paz es el igualitario, fraterno y democrático, entendiendo por democracia igualdad frente al poder, el ingreso, la propiedad y la información desde el nacimiento. El régimen capitalista nunca podrá permitir la democracia, pues en si mismo es fascista, donde el patrón impone sin contrapeso las condiciones de trabajo o de no trabajo. De nada sirven las leyes laborales como hemos constatado, hasta las náuseas, las que, a lo más ajustan la convivencia entre patrones y trabajadores para una mayor explotación en forma pacífica. Es curioso que el modernismo nunca cuestionó al sistema económico como cárcel del ser humano, siendo que la actividad productiva es la 
actividad más fundamental de la sociedad humana y en ella le va su vida y su muerte, no tan solo al que labora sino que a su familia completa. La democracia (votaciones) la dejó, no para resolver los sistemas de convivencia humana y armonía con el ecosistema (lo más importante), sino que para dirimir problemas irrelevantes como tasa de impuestos, relación entre empresas públicas o privadas, relaciones comerciales (sin cuestionar el sistema de comercio) y si iba a tomar té o café. Es curioso que en todo el mundo la gente siga acudiendo a las urnas para elegir entre programas de gobierno alternativos que tiene en común, respecto a los sistemas de convivencia, más del 95\% y crea que con ello vive en democracia. Es totalmente consistente que en el postmodernismo proliferen los grupos Ecologistas, Verdes, Fraternos, Anarquistas, Ácratas, de Economías Alternativas, etc. Por desgracia, la nomología modernista y fascista tiene aún demasiado peso.

No es tan sólo la influencia política del postmodernismo el hito más importante. La convicción del genoma único, irrepetible de cada ser humano ha llevado a una revisión profunda de todas las posturas de los servicios humanos. La educación y acciones de salud postmodernas son personalizadas. En Chile el AUGE, en vez de basarse en personas, garantiza el tratamiento por diagnósticos, entidades conjeturales que no tienen realidad procesal. La Universidad de Chile, dijo yo paso. En educación ya Montessori y Piaget así lo habían concebido. Piaget, quién sabe, el más notable científico del siglo XX, no es mencionado por los filósofos, epistemólogos e historiadores de la ciencia, a pesar de desarrollar su epistemología genética en pleno corazón del post-modernismo. Posiblemente se deba a su crítica lapidaria hacia las ilusiones de la filosofía. Einstein conversando con Piaget, le decía que él no habría podido nunca hacer aportes en temas tan difíciles como los por él abordados. Piaget introduce el estudio de la lógica y de la matemática desde la neuro-psicología (cosa que da, al menos, hipo a muchos matemáticos y lógicos). Si desde Piaget revisamos las proposiciones y teorías lógicas o científicas caeremos en las soluciones dadas por Panza-Gödel. La ciencia helénica y la islámica-escolástica pretendieron intelegir el universo para elevarse a Dios (contemplativa). La ciencia moderna (anglo-sajona) pretendió conocer el universo para dominarlo y obtener de él beneficios económicos y mercantiles (utilitaria). La ciencia postmoderna pretende entender el suceder para liberar al ser humano, y así libre y autónomo pueda optar por Dios, el Diablo o por si mismo (liberadora).

El postmodernismo tiene limitaciones y, según algunos, muchos defectos que no serán tratados aquí, pero aún estos no han merecido ni siquiera una mención en la Universidad de Chile, que hace mucho dejó de ser una Universidad, e incluso para Versidad está cara y no acredita. Para Uni tampoco. 
Polis, Revista de la Universidad Bolivariana, Volumen 9, $N^{\circ}$ 25, 2010

\section{Bibliografía $^{1}$}

Alfonseca, M. (1996), Diccionario Espasa, 1.000 Grandes científicos. Espasa, Madrid.

Aristóteles (1992), Ética Nicomaquea, Política. Editorial Porrua, S. A. México.

Bochenski, I. M. (1968), Historia de la lógica formal. Gredos, Madrid.

Bunge, M. (1983), La investigación científica. Ariel, methodos, Barcelona.

Idem (1985), Racionalidad y realismo. Alianza Universidad, Madrid.

De la Cierva, R. (1995), Las puertas del Infierno. Editorial Fénix. ÁvilaToledo-Madrid.

De Quijano, A. (1606), Equívoco en atribuir mi existencia y muerte a mi engendro mal agradecido y malhechor Miguel de Cervantes. Editorial La Mancha, La Mancha.

Idem (1613), Discurso fúnebre, in memoriam del insigne pensador Don Sancho Panza. Editorial La Mancha, La Mancha.

Descartes, R. (1992), Discurso del Método. Editorial Porrúa, México.

Eliade, M., Couliano, I. P. \& Wiesner, H. S. (1991), The Eliade Guide to World Religions. Harper Collins, San Francisco.

Espoz, R. (2003), De cómo el hombre limitó la razón y perdió la libertad. Editorial Universitaria, Santiago, Chile.

Feyerabend, P. K. (1984), Adiós a la razón. Tecnos, Madrid.

Gödel, K. (1981), Obras Completas. Alianza Universidad, Madrid.

Hawking, S. W. (1989), Historia del tiempo. Editorial Crítica, Barcelona.

Hawking, S. W, y Penrose R. (1993), Cuestiones cuánticas y cosmológicas. Alianza Editorial. Madrid.

\footnotetext{
${ }^{1}$ Notas: 1) biografías sucintas y contribuciones más relevantes de los filósofos y científicos mencionados pueden encontrarse en Alfonseca 1996; pero es sesgado hacia los científicos españoles y varios importantes entre los cuales está J Piaget no aparecen; 2) No he querido poner libros o referencias muy específicas y de desarrollo profundo privilegiando aquellas que puedan ser accesibles y comprensibles a todo lector culto.
} 
Kuhn, T. S. (1970), The structure of Scientific Revolutions. $2^{\circ}$ Ed. The University of Chicago Press, Chicago.

Nagel E. \& Newman, J. R. (1959), Godel's proof. Routledge \& Kegan Paul, London.

Prigogine, I. \& Stengers, I. (1990), Entre el tiempo y la eternidad. Alianza Universidad, Madrid.

Prigogine, I. (1996), El fin de las certidumbres. Andrés Bello, Santiago, Chile.

Popper, K. R. (1994), Búsqueda sin fin. Tecnos, $3^{\circ}$ Ed. Madrid.

Piaget, J. (1972), Psicología y Epistemología. EMECE, Buenos Aires.

Idem (1988), Sabiduría e ilusiones de la Filosofía. Nexos, Barcelona.

Russell, B. (1969), La Perspectiva Científica. Ariel, Barcelona.

San Martín, E. (2005), Todo es efecto de un diseño no del chance. Ayun, Santiago.

Spinoza, B. Ética (1997), Tratado teológico-político. Editorial Porrúa, México.

Valenzuela, C. Y. (1994), “Epistemic restrictions in population biology”, en Biol Res 27: 744-6.

Idem. (2001), "Etica científica y embriones congelados”, en Rev Med Chile 129: 561-8.

Verdú, I. (2001), Tomás Bradwardine. El problema de la libertad. EUNSA, Pamplona. 